\title{
REVISÃO DO GÊNERO ORYSSOMUS MULSANT \\ (COLEOPTERA, COCCINELLIDAE, EXOPLECTRINAE, ORYSSOMINI) E DESCRIC̣ÃO DE GORDONORYSSOMUS, GEN.N.
}

\author{
Lúcia Massutti de Almeida ${ }^{2}$ \\ Iracilda Maria de Moura Lima ${ }^{3}$
}

\begin{abstract}
A REVIEW OF THE genus OrysSomus MUlsant (COleoptera, CocClNELLIDAE, EXOPI.ECTRINAE, ORYSSOMINI) ANI DESCRIPTION OF GORDONORYSSOMUIS, GEN.N.. The Genus Oryssomus is revised and illustrations of pertinent characters are provided. A key to the genera of Oryssomini and to the species of Oryssomus and Gordonoryssomus are added. Gordonoryssomus, gen.n. is described; type species: Onyssomus deyrollei Crotch, 1874. A new species of Oryssomus. O. unimaculatus, sp.n., from Amazonas. Brazil and three of Gordonoryssomus, G. nigrus, sp.n.. from Santa Cruz, Bolivia, G. nigripilosus, sp.n., from Espirito Santo, Brazil and $G$. delicatus, sp.n., from Rio de Janeiro, Minas Gerais, Santa Catarina and Rio Grande do Sul, Brazil, are described.

KEY WORDS. Coccinellidae, Oryssomini, Oryssomus, Gordonoryssomus gen.n.. taxonomy
\end{abstract}

A tribo Oryssomini foi criada por GoRDON (1974) para abrigar os gêneros Oryssomus Mulsant, 1850 e Pseudonoryssomus Gordon, 1974. Um dos caracteres importantes para a tribo era a posse de apenas 10 artículos antenais. No entanto, Oryssomus deyrollei Crotch, 1874 e outras três espécies, até agora desconhecidas, apresentam 11 artículos antenais. Com apoio nesta característica é descrito um novo gênero Gordonoryssomus, para incluir estas espécies. É ainda descrita uma nova espécie de Oryssomus.

$\mathrm{O}$ material utilizado foi cedido para estudo pelas seguintes instituições, às quais agradecemos: Coleção de Entomologia Pe. Jesus Santiago Moure, Departamento de Zoologia da Universidade Federal do Paraná (DZUP), Curitiba, Brasil; Muséum National d'Histoire Naturelle (MNHN), Paris, França; The Natural History Museum (BMNH), Londres, Inglaterra; University Museum of Zoology (UMZC), Cambridge, Inglaterra; National Museum of Natural History (USNM), Washington D.C., Estados Unidos; e Museum für Naturkunde der HumboldtUniversität (ZMHU), Berlim, Alemanha.

1) Contribuição número 912 do Departamento de Zoologia, Universidade Federal do Paraná.

2) Departamento de Zoologia, Universidade Federal do Paraná. Caixa Postal 19020, 81531-990 Curitiba, Paraná. Brasil.

3) Museu de História Natural. Universidade Federal de Alagoas. Rua Aristeu de Andrade 452. 57021-(990 Maceió, Alagoas, Brasil. 


\section{Chave para os gêneros de Oryssomini}

1. Tíbia alargada, achatada e angulosa na margem externa próxima da base . . . . Pseudoryssomus

- Tíhia afilada, sem modificações . . . . . . . . . . . . . . . 2

2. Antena com 10 artículos . . . . . . . . . . Oryssomus

- Antena com 11 artículos. . . . . . . . . . . . Gordonoryssomus, gen.n.

\section{Oryssomus Mulsant 1850}

Oryssomus Mulsant, 1950: 939 (descrição): Croxch, 1874: 292 (Sistemática): Chapuis, 1876: 218 (sistemática); Gorham, 1895: 210 (sistemática): Casey. 1899: 132 (sistemática): Korschefsky, 1931: 176 (catálogo): Blackweld er, 1945: 446 (catálogo): Gordon, 1974: 146 (sistemática). 1987: 35 (catálogo).

Espécie-tipo. Oryssomus subterminatus Mulsant, 1850, por monotipia.

Histórico. O gênero Oryssomus foi descrito por MULSANT (1850) e colocado juntamente com Cranophorus no ramo "Cranophoraires". Em 1974 Gordon criou o gênero Pseudoryssomus que, ao lado de Oryssomus, constituiram a tribo Oryssomini.

Diagnose. Corpo ovalar, robusto, pronoto e élitros brilhantes, com máculas marrons e pilosidade branca-amarelada. Pronoto com bordos anteriores ligeiramente translúcidos. Élitros com calo umeral pouco saliente, epipleura estreita e plana.

Cabeça pequena, profundamente encaixada no protórax. Antenas com dez artículos, o basal robusto e os cinco últimos gradualmente e fortemente alargados, com ápice truncado (Fig. 4). Olhos grossamente facetados. Mandíbulas robustas com dois dentes apicais; mola com um dente curvo; prosteca com cerdas curtas. Palpos maxilares rohustos, fortemente securiformes.

Pronoto com bordo anterior expandido cobrindo totalmente a cabeça. Coxas anteriores transversais, coxas medianas afastadas. Fêmures e tíbias simples, sem espinhos; tarsos com três artículos, garras bífidas e dente basal.

Abdome com cinco segmentos visíveis, linha pós-coxal completa e angulosa, ocupando 2/3 do comprimento do primeiro segmento visível (Fig. 5).

Genitália do macho. Lobo médio fusiforme, com apice afilado, parâmeros largos, com pêlos longos; sifão longo com ápice simples.

Genitália da fêmea. Espermateca robusta e curva.

\section{Chave para as espécies de Oryssomus}

1. Pronoto e élitros amarelados com uma mácula central arredondada marrom escura (Fig. 3) . . . . . . . . . . . . unimaculatus, sp.n.

- Outro padrão de coloração . . . . . . . . . . . . . . . . . . . . 2

2. Pronoto com bordas anterior e laterais marrom avermelhadas; cada élitro com uma mácula arredondada marrom avermelhada subterminal (Fig. 1) . . . . 
subterminatus

- Pronoto anteriormente com duas pequenas máculas marrom avermelhadas; cada élitro com uma faixa marrom avermelhada, em diagonal (Fig. 2) . . . . . .

lineatus

\section{Oryssomus subterminatus Mulsant, 1850}

Figs. 1, 6-9

Oryssomus subterminatus Mulsant, 1850: 939 (descrição): Crotch. 1874: 292 (sistemática). Chapuis. 1876: 218 (sistemática): Gorham, 1895: 210 (sistemática): Korschefsky. 1931: 176 (Catálogo): Blackwelder.1945: 446 (Catálogo). Gordon, 1974: 147 (lectótipo, sistemática): Gordon. 1987: 35 (Catálogo).

Diagnose. Macho com 5,00 mm de comprimento e $3,42 \mathrm{~mm}$ de largura. Corpo oval, robusto, pronoto e élitro brilhantes, negros, densamente pubescentes, com pêlos claros, semidecumbentes; superfície ventral, cabeça e pernas marromavermelhadas. Pronoto mais densamente pontuado que os élitros, com os bordos anterior e laterais marrom-avermelhados, com apenas uma mancha negra na região mediana, estendendo-se da base até quase o ápice; bordo anterior ligeiramente translúcido. Cada élitro com uma mancha arredondada, subterminal alcançando o bordo externo lateral, não atingindo a sutura (Fig. 1). Abdome com linha pós-coxal limitando área de pontuação mais grossa. Genitália: Lobo médio com ápice fendido, menor que os parâmeros, estes largos com pêlos longos (Fig. 6). Sifão longo com ápice simples (Fig. 7).

Fêmea. Semelhante ao macho. Genitália: espermateca fortemente curva, com corno robusto, arredondado, diminuindo o diâmetro na direção da base, esta afilada e bifurcada (Fig. 8). Estilos com pêlos longos (Fig. 9).

Variação intraespecífica. Machos com comprimento variando de 3,67 a $5,00 \mathrm{~mm}$, e largura de 2,75 a $3,42 \mathrm{~mm}$; fêmeas com comprimento entre $3,33 \mathrm{e}$ $5,00 \mathrm{~mm}$, e largura entre 2,42 e $3,50 \mathrm{~mm}$.

Distribuição geográfica. México, Belize, Guatemala, El Salvador, Costa Rica, Panamá, Trinidad y Tobago, Venezuela, Colômbia, Guiana Francesa, Brasil.

Material-tipo. Lectótipo fêmea, designado por GORDON (1974) sem localidade, dissecado parcialmente por Felisberto Camargo (lâmina 836/FCC-1181) depositado no University Museum of Zoology, Cambridge, Inglaterra.

Material examinado. Lectótipo, sem localidade (lâmina 836/FCC-1181), (UMZC). MÉXICO: Fry Coll. 1905, um exemplar, (BMNH). Belize: Blancaneaux (?), um exemplar, (MNHN) (1930, Coll. Sicard). Guatemala: Zapote, G.C. Champion, dois exemplares, (MNHN) (1930, Coll. Sicard). Cacao, Trece Aguas, Alta Vera Paz, Barber \& Schwarz Cool., dois exemplares; (USNM). Zapote, G.C. Champion, B.C.A. Col. dois exemplares, (BMNH). El Salvador: San Salvador, 15-V-1958, L. J. Bottimer; um exemplar; idem, 14-VI-1958, idem, três exemplares (USNM). HoNDURAS: um exemplar (USNM). COSTA RICA: Hamburgfarm, Reventazon, F. Nevermann, 2-IV-1930, um exemplar; Piedras Negras, Coll. Schild \& Burgdorf (USNM). Panamá: Paraiso, Canal Zone, 

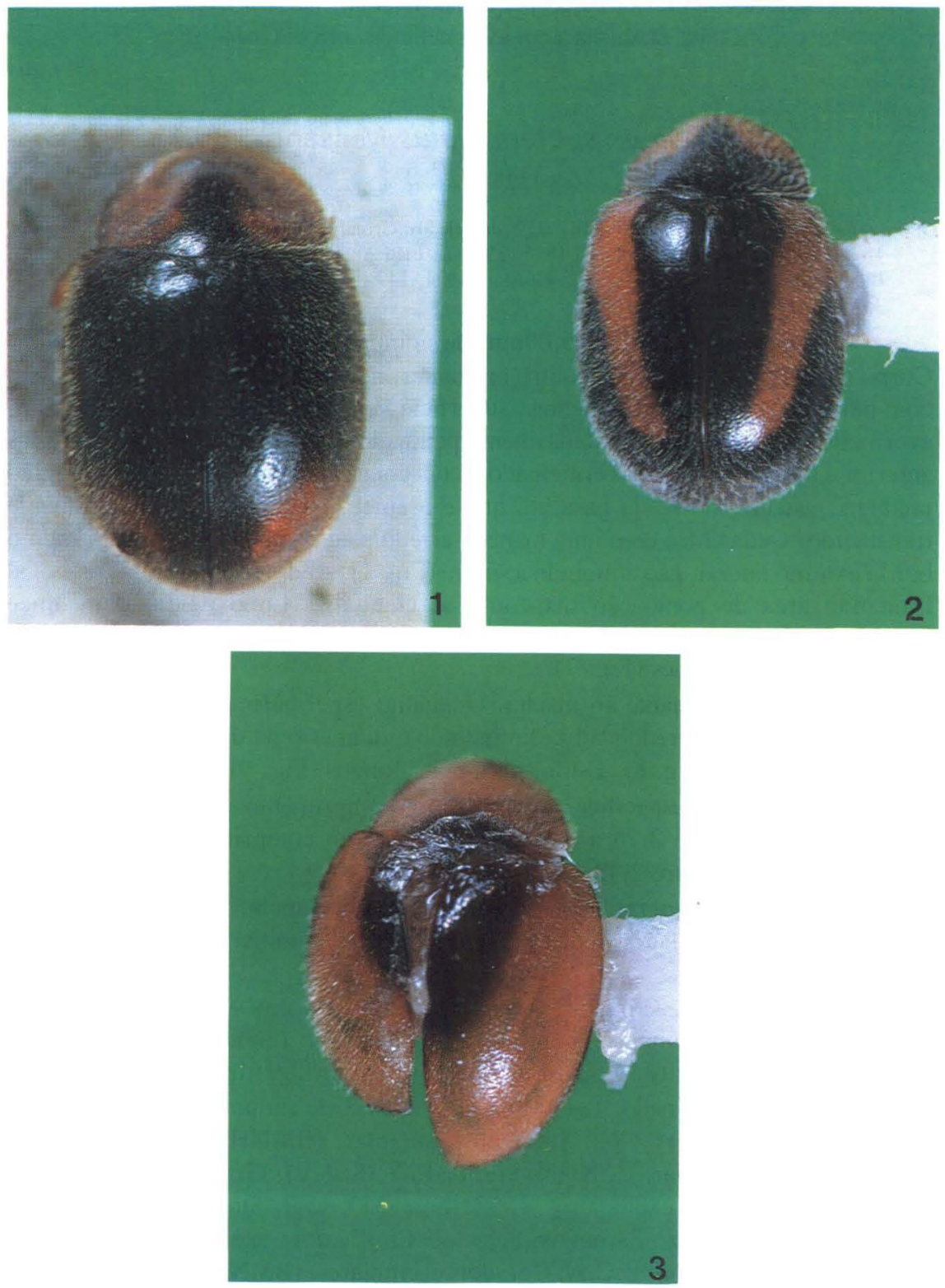

Figs 1-3. (1) Oryssomus subterminatus Mulsant, 1850; (2) O.lineatus Gordon, 1974, parátipo; (3) O. unimaculatus, sp.n., holótipo.

Revta bras. Zool. 12 (3): $701-718,1995$ 

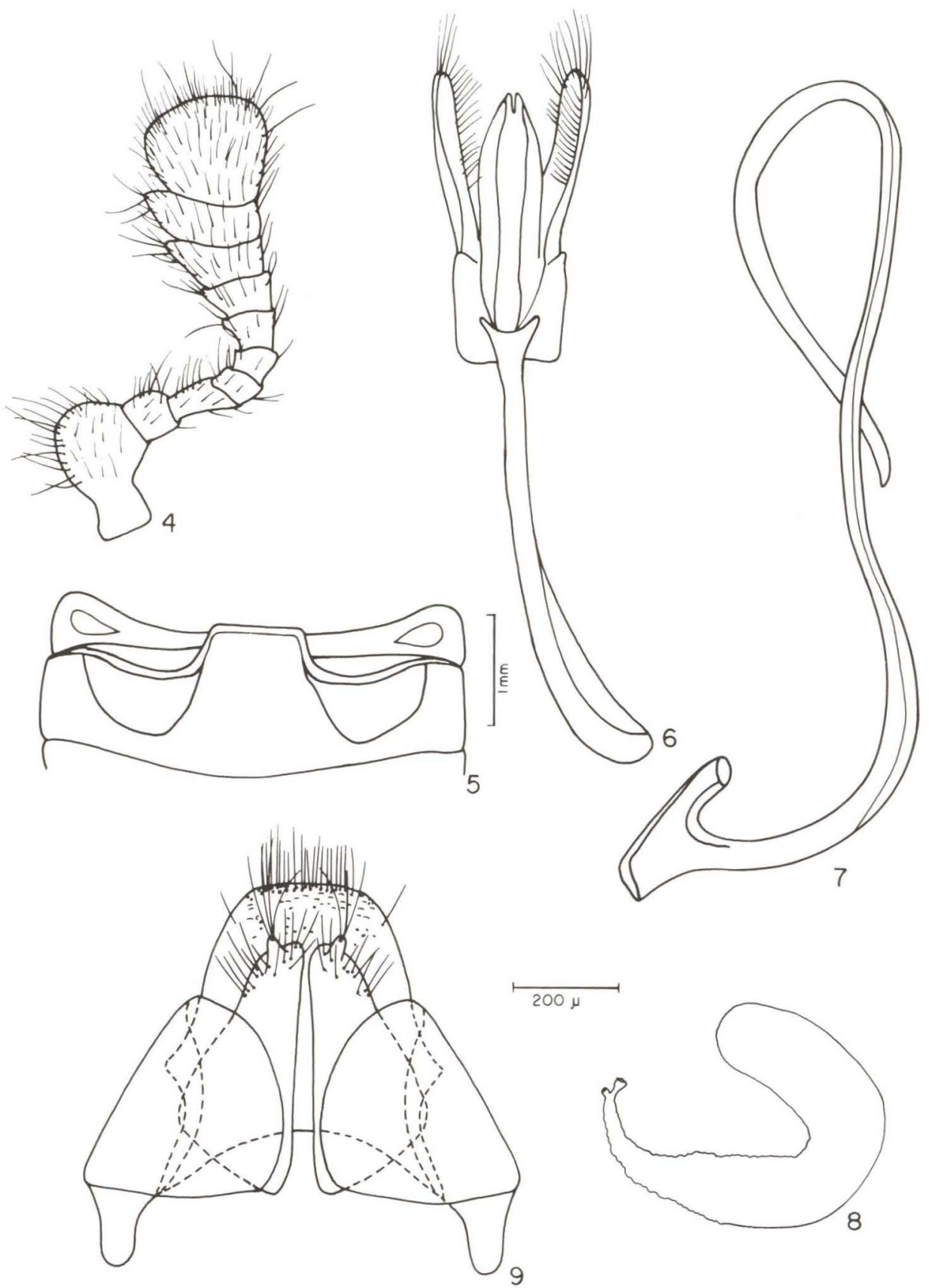

Figs 4-9. Oryssomus subterminatus Mulsant, 1850. (4) antena; (5) primeiro esterno abdominal; (6) tégmem; (7) sifão; (8) espermateca; (9) genitália da fêmea. 
18-I-1911, dois exemplares; 26-I-1911, um exemplar; 5-II-1911, um exemplar; 13-II-1911, um exemplar; 2-IV-1911, um exemplar; 8-IV-1911, um exemplar; 24-IV-1911, dois exemplares; 01-V-1911, três exemplares, E.A. Schwarz Coll. (USNM); Bugaha, Champion, B.C.A. Col., três exemplares (BMNH); Canal Zone, 100m, 5.0mi. NWW Gamboa, 6-IV-1976, Montgomery \& Lubin Coll., um exemplar; Cerro Campana, 18-VII-1976, Wayne E. Clark, um exemplar; Pedro Miguel, 17-IV-1911, E.A. Schwarz, um exemplar; Corazal, 26-IV-1911. Aug. Busck, dois exemplares; La Chorrera, 14-V-1912, Aug. Busck, um exemplar, (Reiche) (USNM). Trinidad Tobago: St. George Province Hillsborough. Dam, 21-III-1979, D. Hardy \& W. Rove, dois exemplares (USNM). VENEZUELA: um exemplar; Caracas, um exemplar, (MNHN 1930, Coll. Sicard); um exemplar (USNM). Venezuela, Stauding, (ZMHU). Guiana Francesa: Cayenne, seis exemplares (MNHN 1930, Coll. Sicard); Cayenne, Coll. Thomson, um exemplar (MNHN); idem, um exemplar (USNM Coll. WmSchaus). ColômBIA: um exemplar (MNHN 1930, Coll. Sicard); Magdalena Parque/Tayrona, $21 \mathrm{mi}$. E. Sta. Marta, V-17-1973, Howden \& Campbell, um exemplar (USNM). BRASIL: um exemplar (MNHN 1930, Coll. Sicard).

\section{Oryssomus lineatus Gordon, 1974}

Figs 2, 10-13

Oryssomus lineatus Gordon. 1974: 148-149 (sistemática)

Diagnose. Macho com $4,08 \mathrm{~mm}$ de comprimento por $3,00 \mathrm{~mm}$ de largura. Corpo oval, robusto, pronoto e élitro brilhantes, negros, densamente pubescentes. com pêlos claros, semidecumbentes; superfície ventral, cabeça e pernas marromavermelhadas. Pronoto mais densamente pontuado que os élitros, com duas pequenas máculas apicais marrom-avermelhadas; bordo anterior ligeiramente translúcido. Cada élitro com uma faixa marrom-avermelhada, em diagonal, desde o calo umeral até os 3/4 do ápice, não atingindo a sutura elitral (Fig. 2). Abdome com linha pós-coxal limitando área com pontuação pouco mais grossa que a da área externa.

Genitália do macho. Loho médio afilando-se gradativamente para o ápice, este arredondado, de comprimento subigual aos parâmeros, estes largos com pêlos longos (Fig. 10). Sifão longo com ápice simples (Fig. 11).

Fêmea. Semelhante ao macho. Genitália: espermateca fortemente curva, com corno afilado, aumentando o diâmetro em direção a base, esta bifurcada (Fig. 12). Estilos muito alongados, com pêlos longos (Fig. 13).

Variação intraespecífica. Machos com comprimento variando de 3,58 a $4,08 \mathrm{~mm}$ e largura de 2,50 a $3,00 \mathrm{~mm}$; fêmeas com comprimento entre 4,08 e $4,58 \mathrm{~mm}$ e largura entre 2,92 e $3,25 \mathrm{~mm}$.

Discussão taxonômica. $O$. lineatus difere de $O$. subterminatus pelo padrão de coloração elitral que nesta espécie apresenta a mancha marrom-avermelhada em faixa diagonal alongada. Em relação à genitália do macho, as duas espécies apresentam padrão semelhante de lobo médio, diferindo apenas na forma do ápice que em $O$. lineatus é mais arredondada; os parâmeros são do mesmo tamanho que 

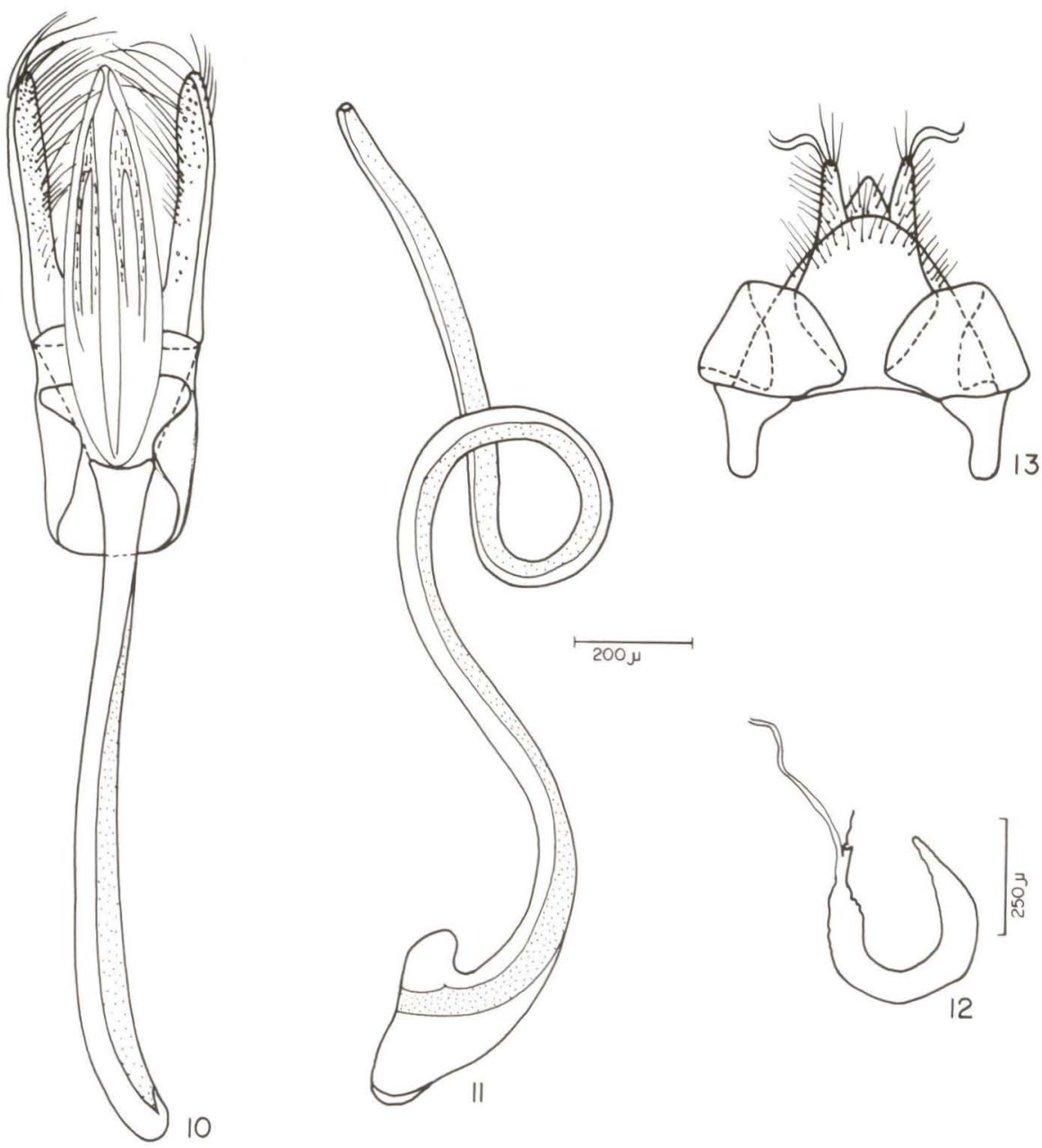

Figs 10-13. Oryssomus lineatus Gordon, 1974. (10) tégmem; (11) sifão; (12) espermateca; (13) genitália da fêmea.

o lobo médio em $O$. lineatus enquanto que em $O$. subterminatus estes são maiores. Quanto à genitália da fềmea, em $O$. lineatus os coxitos apresentam estilos alongados com pêlos longos e espermateca com corno afilado, enquanto que em O. subterminatus os estilos dos coxitos são mais curtos e o corno da espermateca é mais alargado.

Distribuição geográfica. Bolívia; Trinidad y Tobago. 

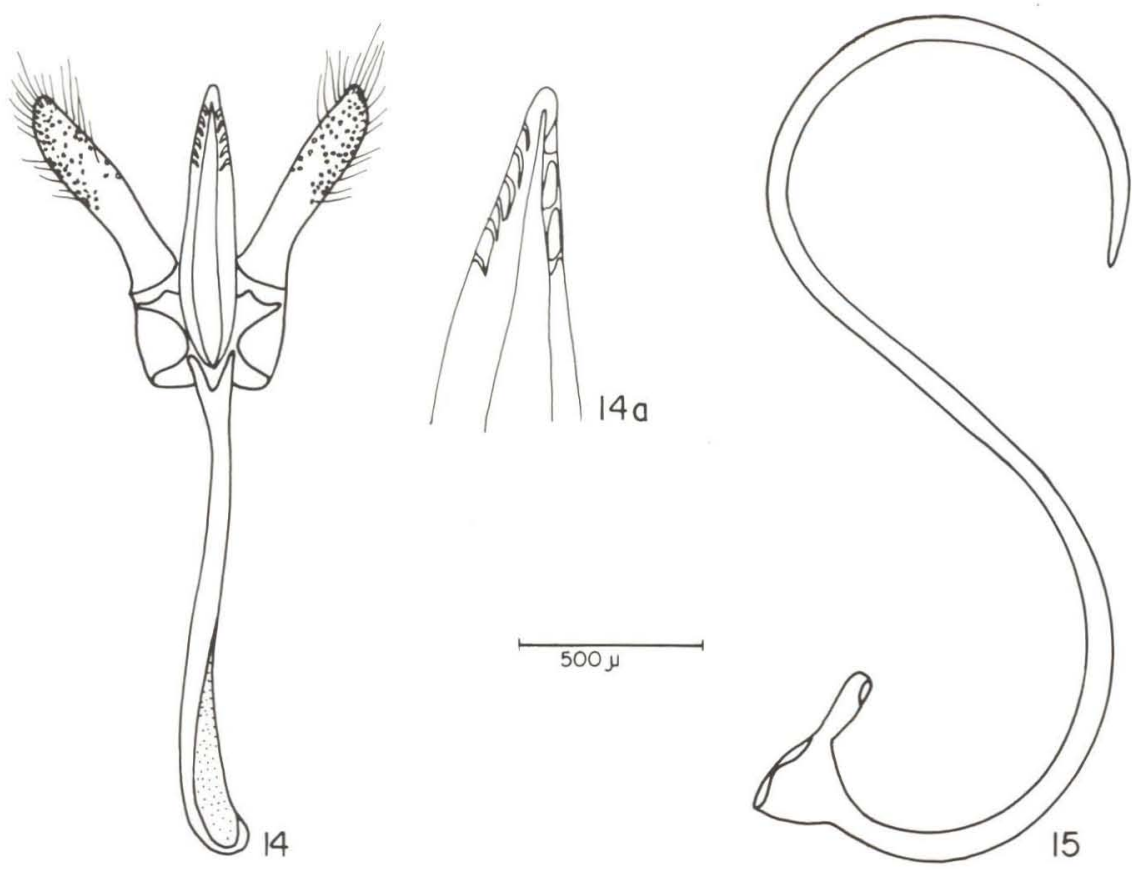

Figs 14-15. Oryssomus unimaculatus, sp.n. holótipo. (14) tégmem; (14a) ápice do lobo médio; (15) sifão.

Material-tipo. Holótipo macho, genitália armazenada em glicerina, Santa Cruz, Bolívia, X-1954, G. Pinckert leg., depositado no National Museum of Natural History, Washington, Estados Unidos; Parátipos, cinco exemplares de Trinidad y Tobago, Summer, 1958, R.R. Bideshi leg., depositados no mesmo Museu.

Material examinado. Bolívia, Santa Cruz: X.1954, G. Pinckert, um macho (Holótipo), USNM. TRINIDAd Tobago: Summer 1958, R.R. Bideshi, cinco exemplares (Parátipos), USNM.

\section{Oryssomus unimaculatus, sp.n.}

Figs $3,14-15$

Diagnose. Macho com 3,83 $\mathrm{mm}$ de comprimento e 2,83 $\mathrm{mm}$ de largura. Corpo oval, pronoto e élitros brilhantes, amarelados, densamente pubescentes, com pêlos claros, semidecumbentes; superfície ventral, cabeça e pernas de mesma coloração. Pronoto com pontuação pouco mais densa que os élitros. Entre o pronoto e élitros uma mácula marrom escura, arredondada, no pronoto estendendo- 
se do terço basal até os três quartos dos élitros (Fig. 3). Abdome com linha pós-coxal arredondada limitando área pouco mais pontuada.

Genitália do macho: Lobo médio afilando-se gradativamente com ápice arredondado e esculturado (Fig. 14a), de comprimento subigual aos parâmeros, estes largos com pêlos longos (Fig. 14). Sifão longo, com ápice simples, afilado (Fig. 15).

Fêmea. Desconhecida.

Discussão taxonômica. Difere das duas espécies anteriores pelo padrão de coloração elitral que nesta espécie é amarelada com uma única mácula arredondada central. A genitália do macho nesta espécie tem ápice do lobo médio simples, afilado e arredondado, enquanto que em $O$. subterminatus o ápice é féndido e em $O$. lineatus o ápice é pouco mais alargado.

Distribuição geográfica. Brasil, Amazonas.

Material tipo. Holótipo macho, (genitália armazenada em glicerina), Manaus, Amazonas, Brasil, VI-1972, F. Oliveira leg., depositado na Coleção de Entomologia Pe. Jesus Santiago Moure, do Departamento de Zoologia da Universidade Federal do Paraná.

Material examinado. Brasil, Amazonas: VI-1972, F. Oliveira leg., holótipo macho, DZUP.

Comentários. Este exemplar está com um élitro um pouco mal formado, porém sua coloração característica, hem como o padrão de genitália permitem reconhecer facilmente a espécie.

\section{Gordonoryssomus, gen.n.}

Espécie-tipo: Oryssomus deyrollei Crotch, 1874.

Diagnose. Corpo ovalar, robusto, pronoto e élitros marrom avermelhados ou negros, brilhantes, com densa pilosidade. Pronoto com bordo anterior ligeiramente translúcido. Élitros com calo umeral pouco saliente, epipleura estreita e plana. Cabeça profundamente encaixada no protórax. Antenas com 11 artículos, o basal robusto e os cinco últimos gradual e fortemente alargados, com ápice truncado, os três artículos apicais mais largos e muito unidos entre sí (Fig. 20). Olhos grossamente facetados. Mandíbulas robustas com dois dentes apicais, mola com dente curvo, prosteca com cerdas curtas (Fig. 21). Palpos maxilares robustos, fortemente securiformes (Fig. 22).

Pronoto com bordo anterior expandido cobrindo totalmente a cabeça. Coxas anteriores transversais; coxas medianas afastadas, fêmures e tíbias simples, sem espinhos; tarsos com três artículos, garras bífidas e dente basal.

Abdome com cinco segmentos visíveis, densamente pontuado, com maior concentração de pontos nos primeiros três esternos. Linha pós-coxal completa e arredondada (Fig. 30), exceto em G. deyrollei (Fig. 23), ocupando 2/3 do comprimento do primeiro segmento visível.

Genitália do macho. Lobo médio a filado no ápice, parâmeros largos, com pêlos longos; sifão longo, com ápice simples. 

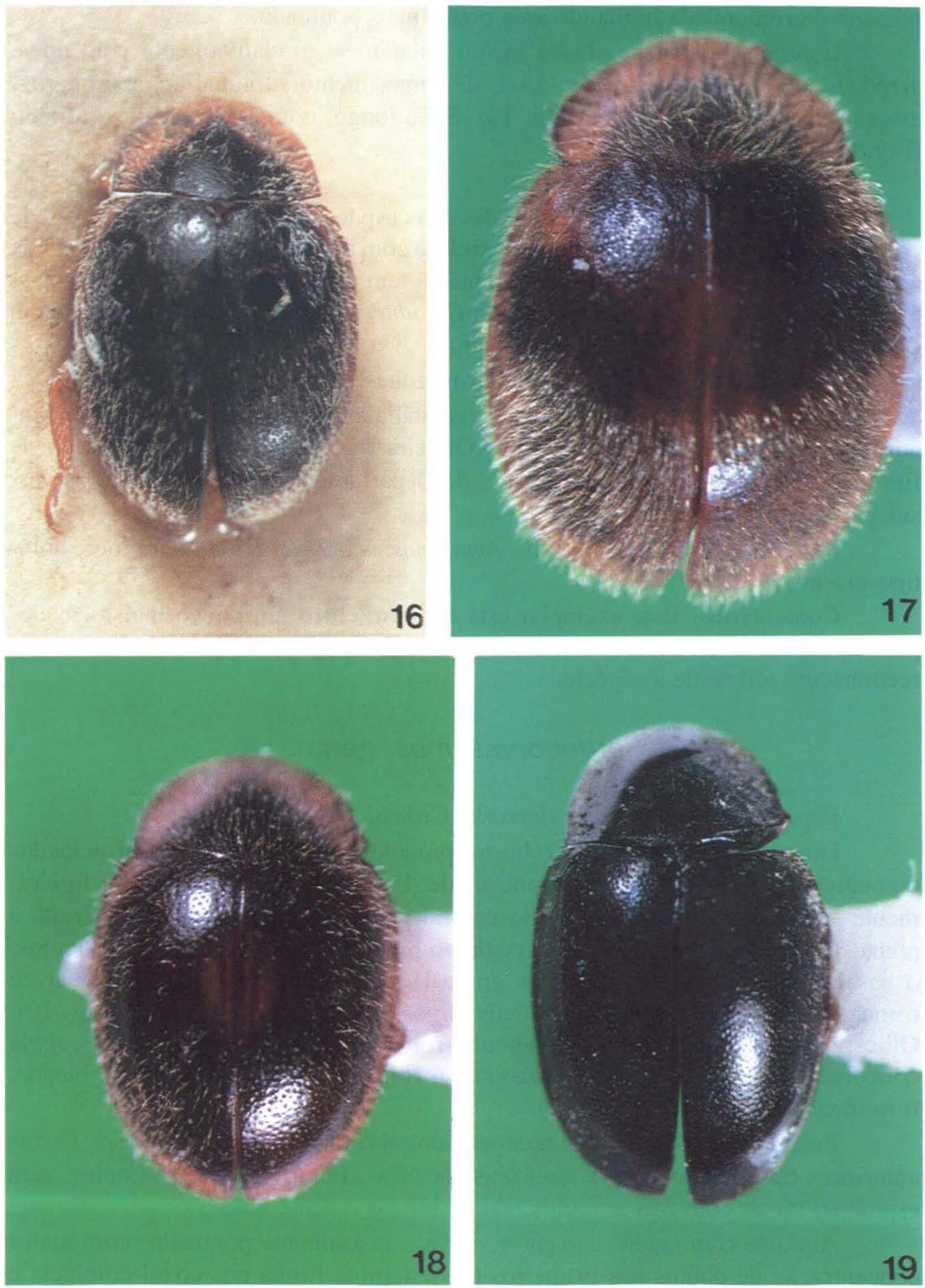

Figs 16-19. (16) Gordonoryssomus deyrollei (Crotch, 1874) holótipo; (17) G.nigripilosus, sp.n., holótipo; (18) G. nigrus, sp.n. holótipo; (19) G. delicatus, sp.n. holótipo. 
Genitália da fêmea. Espermateca robusta, curva, com corno arredondado e base longa, afilada e hifurcada.

Discussão taxonômica. A diferença entre Oryssomus e Gordonoryssomus está no número de artículos da antena e na forma dos três artículos apicais. A linha pós-coxal em Gordonoryssomm. . dentro das espécies do gênero. Essa mesma variação também ocorre no gêner Pseudonoryssomus.

\section{Chave para as espécies de Gordonoryssomus}

1. Élitros negros com pilosidade branco-amarelada, sem máculas . . . . . . . . 2

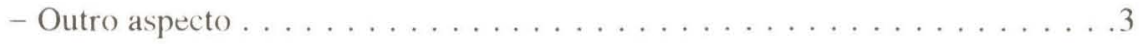

2. Pronoto com bordas laterais alaranjadas(Fig. 18) . . . . . nigrus, sp.n.

- Pronoto e élitros com bordas laterais alaranjadas (Fig. 16) . . . . . . de deyrollei

3. Pronoto e élitros marrom-avermelhados: élitros com mácula basal formada por pilosidade negra (Fig. 17) . . . . . . . . . nigripilosus, sp.n.

- Pronoto e élitros negros, com bordas laterais alaranjadas; pequena mácula oval alaranjada na sutura elitral (Fig. 19) . . . . . . . . delicatus, sp.n.

\section{Gordonoryssomus deyrollei (Crotch, 1874), n.comb.}

Figs $16,23-27$

Onjssomus deyrollei Crotch. 1874: 292 (descrição): Korschetsky. 1931: 176 (catálogo): Blackwelder. 1945: 446 (catálogo): Gordon. 1974: 147 (sistemática): Gordon, 1987: 35 (catálogo).

Diagnose. Macho com $5,00 \mathrm{~mm}$ de comprimento e $3,60 \mathrm{~mm}$ de largura. Corpo oval, robusto, pronoto e élitros negros, brilhantes, densamente pubescentes, com pêlos branco-amarelados, semidecumbentes, superfície ventral, cabeça e pernas marrons avermelhadas. Pronoto mais densamente pontuado que os élitros, bordo anterior translúcido. Pronoto e élitros com as margens externas alaranjadas (Fig. 16). Abdome com linha pós-coxal angulosa (Fig. 23).

Genitália do macho. Lobo médio muito afilado no ápice, este esculturado, com pêlos na porção mediana (Fig. 24a), de comprimento maior que os parâmeros, estes largos com pêlos longos (Fig. 24). Sifão longo com ápice simples (Fig. 25).

Fêmea. Semelhante ao macho. Genitália: espermateca curva, com corno afilado e base bifurcada (Fig. 26). Estilos com conspícuos pêlos longos (Fig. 27).

Variação intraespecífica. Machos com comprimento variando de 4.08 a $5,00 \mathrm{~mm}$ e largura de 3,33 a $4,00 \mathrm{~mm}$; fêmeas com comprimento entre 5,17 e $5,83 \mathrm{~mm}$ e largura entre 3,90 e $4,10 \mathrm{~mm}$.

Distribuição geogrática. Brasil e Chile.

Material-tipo. Holótipo macho, sem localidade, "Type" etiqueta azul, Deyrollei, Brasil, dissecado parcialmente por Felisberto C. Camargo, lâmina 831/FCC-1176, está depositado no University Museum of Zoology, Cambridge, Inglaterra.

Material examinado. BRAsiL: Coleção Deyrolle, holótipo, um exemplar, 


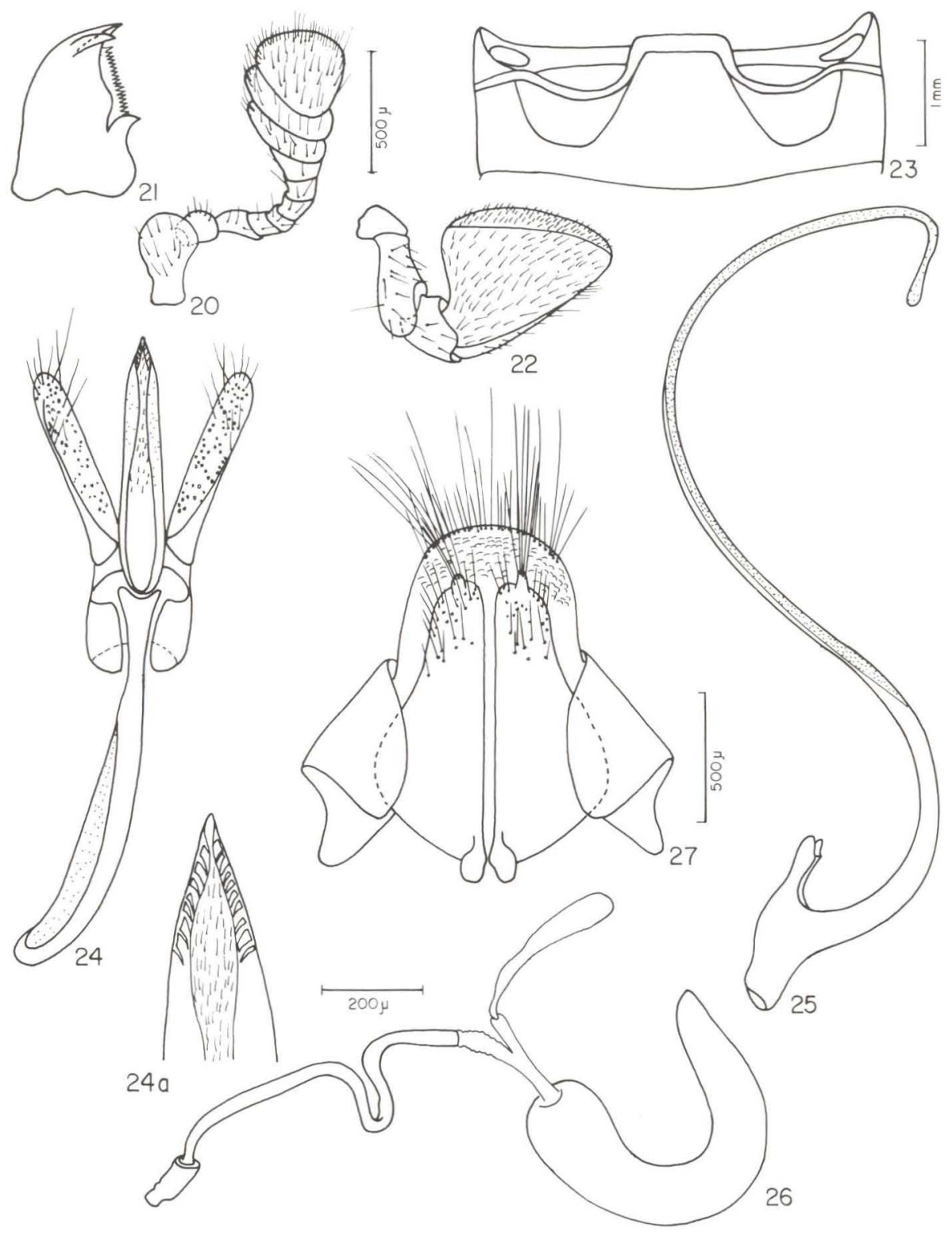

Figs 20-27. (20) Gordonoryssomus deyrollei (Crotch, 1874). (20) antena; (21) mandíbula; (22) palpo maxilar; (23) primeiro esterno abdominal; (24) tégmem; (24a) ápice do lobo médio; (25) sifão; (26) espermateca; (27) genitália da fêmea.

Revta bras. Zool. 12 (3): $701-718,1995$ 
UMZC; Rio de Janeiro: Terezópolis, 28-V-1939, F.C. Camargo leg. (lâmina 814/FCC-1159), um exemplar (MNRJ); Minas Gerais: Vila Monte Verde, 8-II1965, J. Halik, (homótipo, indicado por Gordon, 1988) (USNM); Santa Catarina: Seara (Nova Teutônia), X-1947, um exemplar; VII-1959, um exemplar; X-1974, três exemplares; III-1977, um exemplar; X-1980, quatro exemplares, F. Plaumann leg. (DZUP); Lages, Hochland, Fruhstorfer S., um exemplar (ZMHU). CHILE: Germain, dois exemplares (MNHN Coll. Sicard).

\section{Gordonoryssomus nigripilosus, sp.n.}

Figs $17,28,29$

Diagnose. Macho com $8,52 \mathrm{~mm}$ de comprimento e $6,83 \mathrm{~mm}$ de largura. Corpo oval, robusto, grande, pronoto e élitros vermelho-alaranjados, brilhantes, densamente pubescentes, com pêlos brancos e negros, semidecumbentes. Superfície ventral, cabeça e pernas marrom avermelhadas. Pronoto com bordo anterior translúcido, com uma área central mais escura e pêlos claros. Élitros com a metade basal mais escura em função da diferença na coloração dos pêlos. Esta área de pêlos negros não abrange o calo umeral e tem o ápice arredondado (Fig. 17). Abdome com linha pós-coxal arredondada.

Genitália do macho: Lobo médio com pequena constrição no ápice, este arredondado e esculturado, com pêlos na porção mediana (Fig. 28a), de comprimento subigual aos parâmeros, estes largos e com pêlos longos (Fig. 28). Sifão longo com ápice simples (Fig. 29).

Fêmea. Desconhecida.

Distribuição geogrática. Brasil (Espírito Santo).

Material-tipo. Holótipo macho. BRASIL, Espirito Santo: genitália armazenada em glicerina, depositado no Muséum National d’Histoire Naturelle, Paris, França.

Material examinado. Holótipo macho, Espírito Santo, BRASIL (etiqueta verde: Muséum Paris, 1930, Coll. SiCARD), MNHN.

Discussão Taxonômica. G. nigripilosus difere de G. deyrollei pelo tamanho muito maior, pelo padrão geral de coloração e pela genitália do macho.

\section{Gordonoryssomus nigrus, sp.n.}

Figs $18,30-32$

Diagnose. Macho com 4,50mm de comprimento e $3,00 \mathrm{~mm}$ de largura. Corpo ovalar, robusto, pronoto e élitros negros, brilhantes, com pêlos brancoamarelados, semidecumbentes, superfície ventral, cabeça e pernas marrom avermelhadas. Pronoto com os bordos laterais alaranjados e área central negra. Élitros negros, sem máculas (Fig. 18). Abdome com linha pós-coxal arredondada (Fig. 30).

Genitália do macho. Lobo médio afilando-se para o ápice, este arredondado, simples (Fig. 31a), menor que os parâmeros, estes largos e com pêlos longos (Fig. 

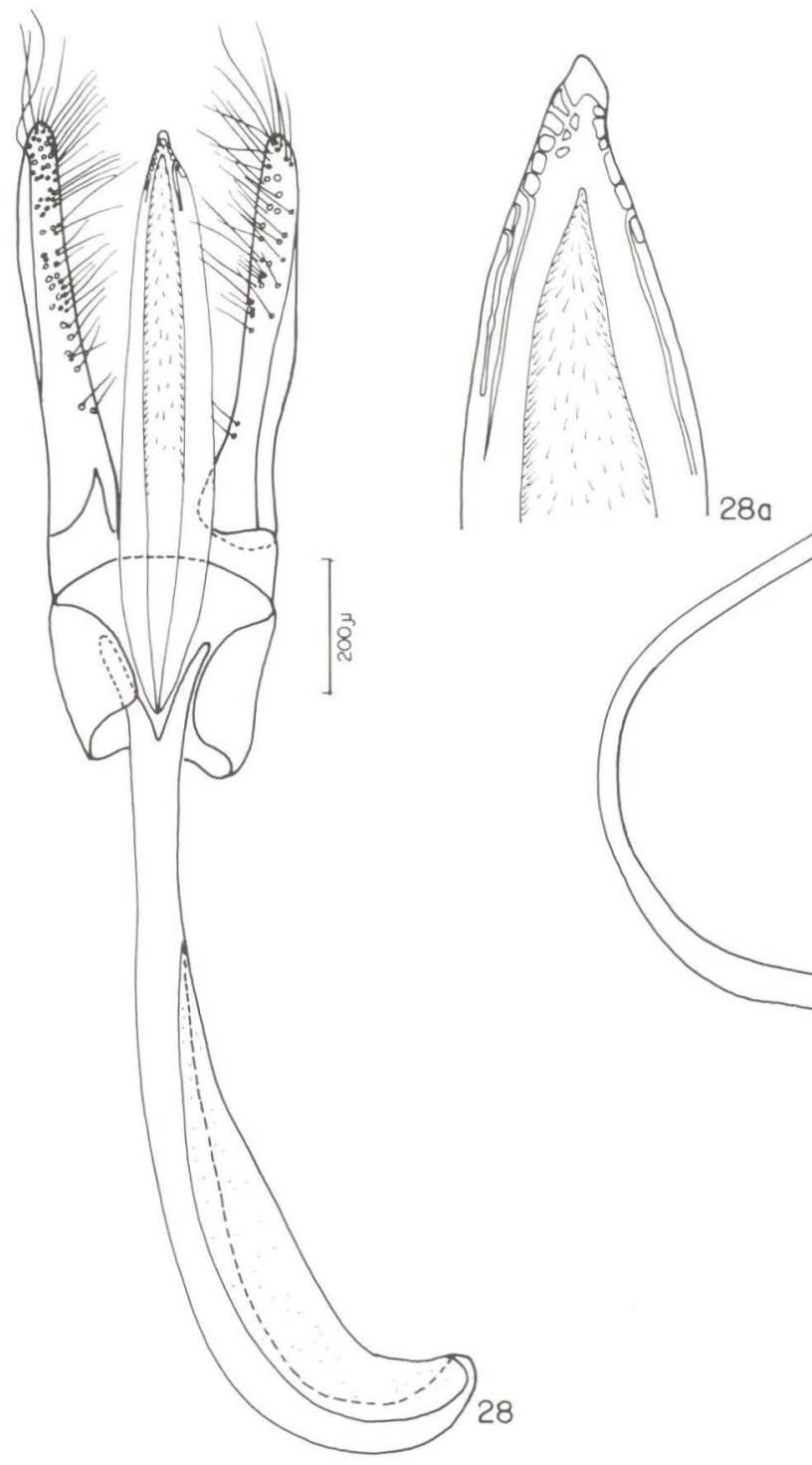

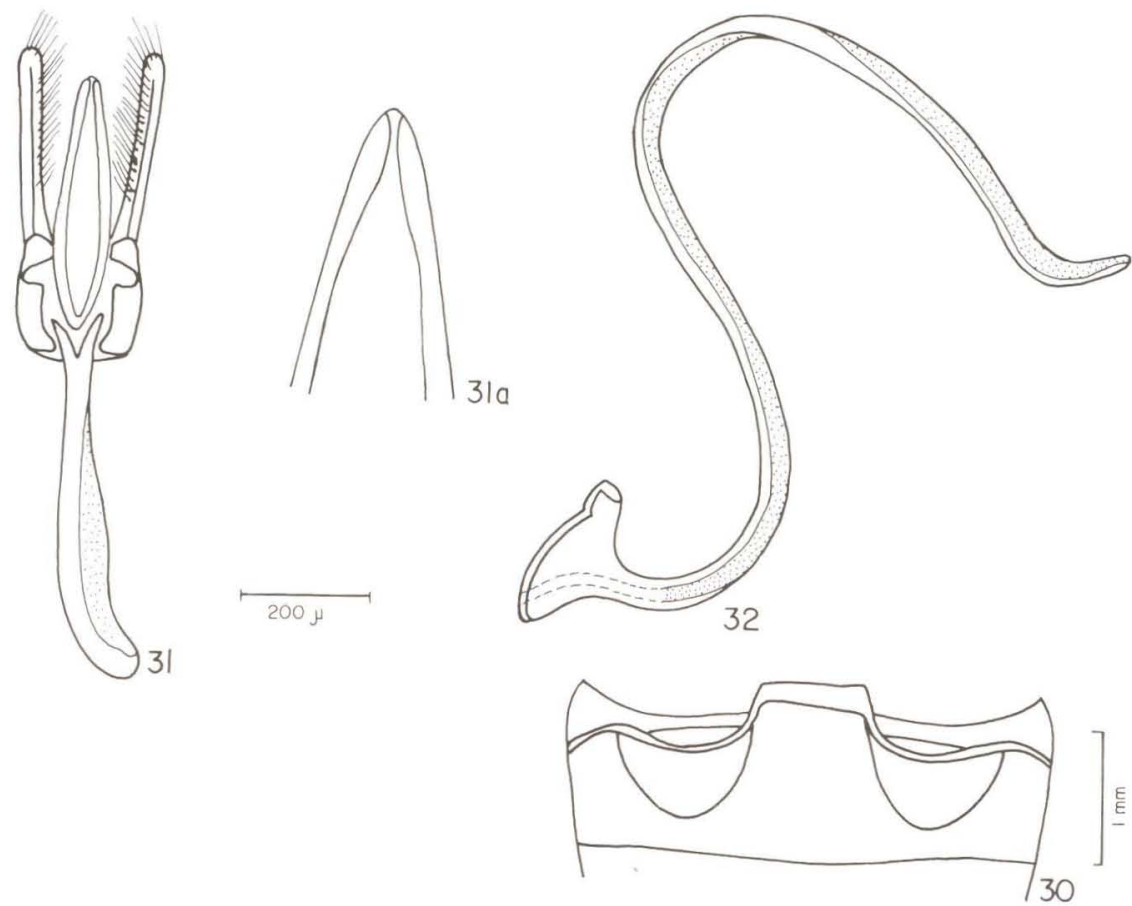

Figs 30-32. Gordonoryssomus nigrus, sp.n. holótipo. (30) primeiro esterno abdominal; (31) tégmem; (31a) ápice do lobo médio; (32) sifão.

31). Sifão alongado com ápice simples (Fig. 32).

Fêmea. Desconhecida.

Distribuição geográfica. Bolívia.

Material-tipo. Holótipo macho. Bolívia, Santa Cruz: Limon, depositado no National Museum of Natural History, Washington, D.C., Estados Unidos.

Material examinado. Bolívia, Santa Cruz: Limon, IX-1929, G.L. Harrington leg., USNM.

Discussão taxonômica. G. nigrus difere de G. nigripilosus pelo tamanho, padrão de coloração e genitália do macho e difere de $G$. deyrollei pela coloração, pela linha pós-coxal e genitália do macho.

\section{Gordonoryssomus delicatus, sp.n.}

Figs 19, 33-36

Diagnose. Macho com 4,17mm de comprimento e 2,92mm de largura. Corpo ovalar, pronoto e élitros negros, brilhantes, com pêlos branco-amarelados, semidecumbentes, superfície ventral, cabeça e pernas marrom avermelhadas. Pronoto com bordo anterior translúcido. Pronoto com as margens alaranjadas e área central negra. Élitros negros, com margens laterais alaranjadas e uma pequena 

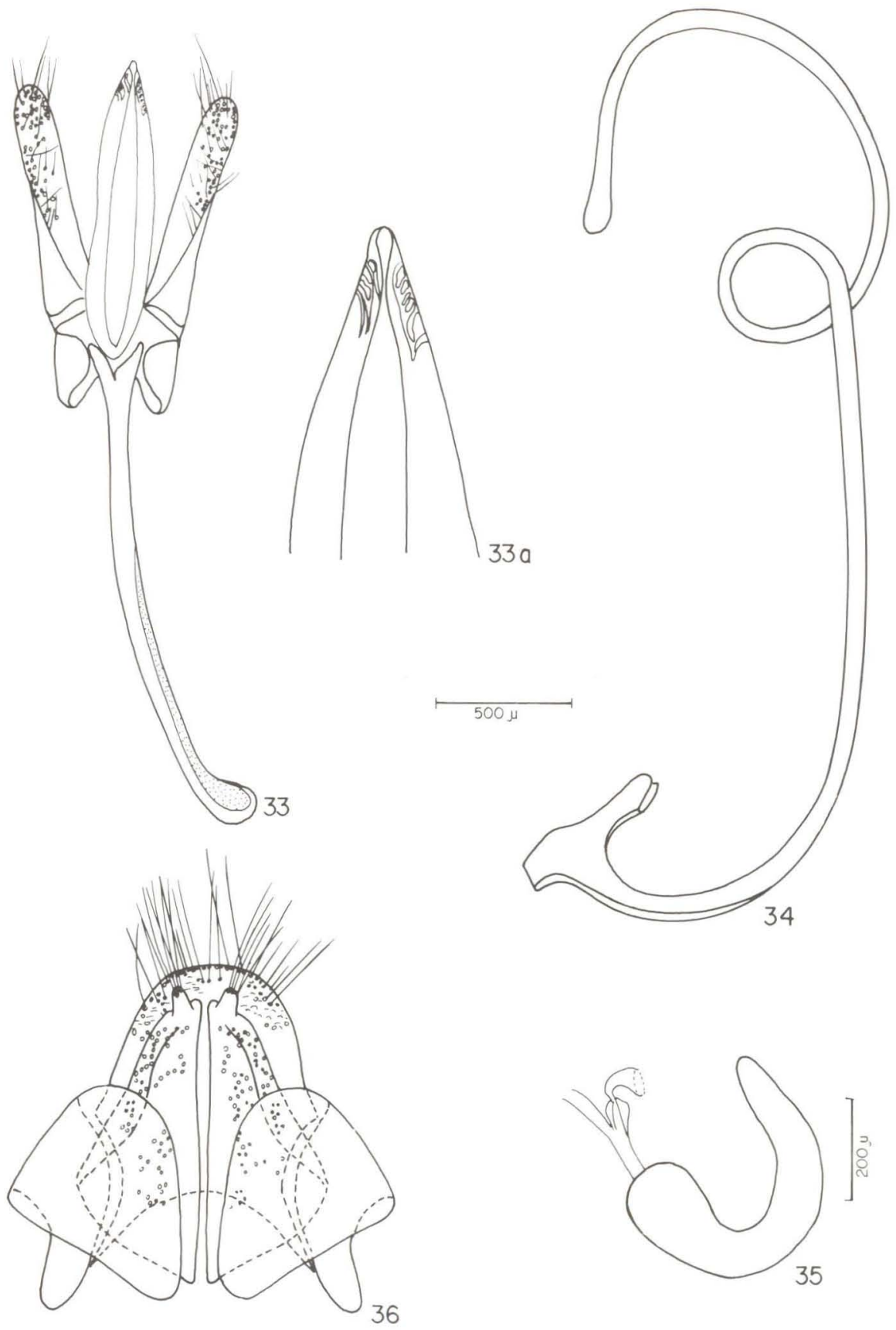

Figs 33-36. Gordonoryssomus delicatus, sp.n. holótipo. (33) tégmem; (33a) ápice do lobo médio; (34) sifão; (35) espermateca; (36) genitália da fêmea. 
mácula oval alaranjada na sutura elitral (Fig. 19). Abdome com linha pós-coxal arredondada.

Genitália do macho. Lobo médio a filando-se para o ápice, este arredondado, com pequena constrição, esculturado (Fig. 33a), maior que os parâmeros, estes largos com pêlos longos (Fig. 33). Sifão muito longo com ápice simples (Fig. 34).

Fêmea. Semelhante ao macho. Genitália: espermateca curva, com corno afilado e base bifurcada (Fig. 35). Estilos conspícuos com pêlos longos. (Fig. 36).

Variação intraespecífica. Machos com comprimento variando de 4,17 a $4,83 \mathrm{~mm}$ e largura de 2,92 a $3,33 \mathrm{~mm}$; fêmeas com comprimento entre 4,83 e $5,42 \mathrm{~mm}$ e largura entre 2,92 e $3,33 \mathrm{~mm}$.

Distribuição geográfica. Brasil.

Material-tipo. Holótipo macho. "Brasilien, Nova Teutonia, VII/45, Fritz Plaumann", depositado na Coleção de Entomologia Pe. Jesus Santiago Moure do Departamento de Zoologia da Universidade Federal do Paraná. Parátipos, os demais exemplares, listados em material examinado e depositados no mesmo Museu, no National Museum of Natural History, Washington, Estados Unidos, no The Natural History Museum, Londres, Inglaterra e no Museum für Naturkunde der Humboldt-Universität zu Berlin, Alemanha.

Material examinado. Brasil, Rio de Janeiro: Lagoa de Saquarema, VIIIIX-1884, P. Germain, parátipo, um exemplar (USNM); 1903-180, (?), Wagner, um exemplar (BMNH); Minas Gerais: Viçosa, 13/10-1/11-1985, T.J. Henry \& S.P. Fiuza F. leg., parátipo, um exemplar (USNM); Santa Catarina: Seara, Nova Teutônia, V-II-1944, parátipo, um exemplar; VII-1945, holótipo, um exemplar, F. Plaumann (DZUP); Rio Grande do Sul: Rio Grande, um exemplar (ZMHU).

Discussão taxonômica. G. delicatus difere de $G$. deyrollei pela presença de mácula central no élitro e pela genitália do macho que apresenta ápice do lobo médio mais arredondado. Difere de $G$. nigrus pelo padrão de coloracão do corpo e pela genitália do macho que apresenta os parâmeros mais curtos que o lobo médio.

AGRADECIMENTOS. Ao Prof. Dr. Renato C. Marinoni pela leitura crítica do texto e ao Prof. Dr. Albino M. Sakakibara pelas fotografias dos exemplares.

\section{REFERÊNCIAS BIBLIOGRÁFICAS}

BlackWELDER, R.E. 1945. Checklist of Coleopterous Insects of Mexico, Central America, the West Indies, and South America, U.S. Nat. Mus. Bull. 185 (3): $1-188$.

Casey, T.L. 1899. A revision of the American Coccinellidae. J. New York Entomol. Soc. 7: 71-169.

ChapuIs, F. 1876. Famille des phytophages des érotyliens des endomychides et des coccinellides. 12, p.1-424 In: J.T. LACORdaire \& F. Chapuis (eds). Histoire naturelle des insectes. Genera des Coléoptères.

Crotch, G.R. 1874. A revision of the Coleopterous family Coccinellidae. London, $311 \mathrm{p}$. 
Gordon, R.D. 1974. A review of the Oryssomini, a new of Tribe of Neotropical Coccinellidae (Coleoptera). Coleopt. Bull. 28 (3): 145-154. . 1987. A catalogue of the Crotch collection of Coccinellidae (Coleoptera).

Oc. Pap. Syst. Ent. 3: 1-46.

Gorham, H.S. 1895. Biologia Centrali-Americana, Insecta, Coleoptera, Coccinellidae. 7: 209-216.

Korschewsky, R. 1931. Coleopterorum Catalogus. 16 (118), Coccinellidae p. 1-224.

Mulsant, E. 1850. Species de colèoptères trimères sécuripalpes. Ann. Sci. Phys. Nat., Lyon, 2 (2): 1-1104.

Weise, J. 1895. Neue Coccinelliden, sowie Bemerkungen zu bekannten Arten.

Ann. Soc. ent. Belgique 39: 120-146.

Recebido em 25.XI.1995; aceito em 20.XII.1995. 